\title{
ANALISIS KINERJA SISTEM PENDINGIN RUANG PALKAH IKAN DENGAN MENGGUNAKAN REFRIGERAN R-22 DAN HIDROKARBON (MC-22)
}

\author{
Amri Jumhan, Audry D Cappenberg \\ Program studi Teknik Mesin Universitas 17 agustus 1945 Jakarta \\ amrijumhan.aj@gmail.com
}

\begin{abstract}
ABSTRAK
Proses pendinginan atau refrigerasi sangat diperlukan oleh nelayan untuk mempertahankan mutu dari hasil tangkapan ikan. Dan perlu adanya teknologi pendinginan ikan yang mampu digunakan dalam jangka waktu lama. Teknik refrigerasi modern yang digunakan dengan mengaplikasikan refrigeran sebagai media utama pengganti es balok. Pada saat ini, refrigeran yang umum dipakai dalam proses pendinginan yaitu dengan menggunakan jenis R-22 yang ke depannya harus digantikan dengan refrigeran lain yang lebih ramah lingkungan dan aman. Penelitian ini dilakukan untuk mencoba mengganti dengan refrigeran hidrokarbon MC-22 pada sistem pendingin kompresi uap. Pada penelitian ini difokuskan pada kinerja kompresor dan koefisien prestasi pada objek kapal KM. Putra Berlian dengan kapasitas muatan ikan mencapai 100 ton. Dari analisis yang telah dilakukan refrigeran keluar dari evaporator $-20^{\circ} \mathrm{C}$. Refrigeran keluar dari kompresor $40^{\circ} \mathrm{C}$. Refrigeran keluar dari kondensor $32^{\circ} \mathrm{C}$. Dan refrigeran keluar katup ekspansi menuju evaporator $-20^{\circ} \mathrm{C}$ dengan daya pendingin $60 \mathrm{~kW}$. Dari penghitungan pada sistem refrigerasi ini didapat hasil bahwa terdapat kenaikan kerja kompresor $45 \%$ dan penurunan COP $45 \%$.
\end{abstract}

Kata kunci : $\quad$ refrigerasi, kapal ikan, refrigeran R-22, refrigeran MC-22, kompresor, COP.

\section{PENDAHULUAN}

\subsection{Latar Belakang}

Proses pendinginan atau refrigerasi sangat diperlukan oleh nelayan untuk mempertahankan mutu dari hasil tangkapan ikan. Pada akhir-akhir ini sistem refrigerasi sangat pesat perkembangannya seiring dengan perkembangan zaman. Teknik refrigerasi modern yang digunakan dengan mengaplikasikan refrigeran sebagai media utama pengganti es balok pada teknik pendinginan atau refrigerasi konvensional. Penerapan teknik refrigerasi mencakup pemrosesan dan pengawetan terlebih pada sektor perikanan.

Sampai saat ini proses pendinginan ikan yang dilakukan nelayan tradisional di Indonesia pada umumnya menggunakan es balok,akan tetapi sebetulnya jika kita analisis baik secara teknis maupun ekonomis, maka banyak kelemahan dalam sistem pendingin es tersebut. Dari sisi teknis, dengan adanya es sebagai media pendingin, maka berat esnya akan menjadikan berat kapal bertambah, sehingga menambah tahanan kapal yang sebetulnya harus dihindari karena dampak selanjutnya mesin utama akan membutuhkan konsumsi bahan bakar yang besar. Selain itu

Jurnal Kajian Teknik Mesin

Vol. 2 No. 1 April 2017 
harga ikan yang turun karena kualitas ikan hasil tangkapan yang rendah karena proses pendinginan ikan yang bertujuan untuk menjaga kualitas ikan segar kurang sempurna. Penurunan mutu ini diakibatkan karena adanya aktivitas bakteri, aktivitas enzim, maupun kombinasi dari faktor-faktor tersebut. Salah satu alternatif lain yang dapat di gunakan untuk menjaga kualitas ikan segar adalah dengan menggunakan sistem pendingin.

\subsection{Tujuan Penelitian}

Adapun tujuan penelitian ini yaitu :

1) Menganalisis daya kompresor dan efisiensi dari penggunaan refrigeran

a. Freon R-22

b. Hidrokarbon MC-22

2) Menganalisis koefisien prestasi (COP) dari penggunaan refrigeran
a. Freon R-22
b. Hidrokarbon MC-22

\section{TINJAUAN PUSTAKA}

\subsection{Pengertian Perpindahan Kalor}

Perpindahan kalor (heat transfer) adalah ilmu untuk meramalkan atau mempelajari tentang laju perpindahan energi (panas/kalor) pada material, benda atau media lainnya yang terjadi karena adanya perbedaan temperatur/suhu(Holman J.P, 1994). Perbedaan suhu yang dimaksud adalah lebih dingin atau lebih panas. Kalor/panas akan mengalir dari suhu yang lebih tinggi ke suhu yang lebih rendah. Termodinamika mengajarkan bahwa transfer energi ini didefinisikan sebagai kalor/panas. Namun, perpindahan kalor berbeda dengan termodinamika.Termodinamika berkaitan dengan sistem dalam kesetimbangan, dapat digunakan untuk memprediksi jumlah energi yang dibutuhkan untuk mengubah sistem dari keadaan setimbang ke keadaan lainnya, tetapi tidak dapat memprediksi seberapa cepat perubahan akan terjadi karena sistem tidak dalam keseimbangan selama proses terjadi.

Ilmu perpindahan kalor tidak hanya mencoba untuk menjelaskan bagaimana energi panas itu berpindah dari suatu benda ke benda lain, tetapi juga meramalkan seberapa cepat laju perpindahan kalor yang terjadi pada kondisi-kondisi tertentu. Maka dari itu dapat disimpulkan bahwa antara termodinamika dan perpindahan kalor saling berhubungan dan melengkapi.

\subsection{Cara-cara Perpindahan Kalor}

\subsubsection{Perpindahan Kalor Secara Konduksi}

Perpindahan kalor secara konduksi adalah proses perpindahan kalor dimana kalor mengalir dari daerah yang bersuhu tinggi ke daerah yang bersuhu rendah dalam suatu medium (padat, cair atau gas) atau antara medium-medium yang berlainan yang bersinggungan secara langsung.

\subsubsection{Perpindahan Kalor Secara Konveksi}

Perpindahan kalor secara konveksi adalah proses perpindahan energi (kalor) dengan kerja gabungan dari konduksi kalor, penyimpanan energi dan gerakan mencampur. Konveksi sangat penting sebagai mekanisme perpindahan energi antara permukaan benda padat dan cair atau gas. Umumnya proses konveksi terjadi pada benda cair dan gas, bukan benda padat. Perpindahan kalor secara konveksi dari suatu permukaan yang suhunya di atas suhu fluida disekitarnya berlangsung dalam beberapa tahap. Pertama, kalor akan mengalir dengan cara konduksi dari permukaan ke partikel-partikel fluida yang berbatasan. Energi yang berpindah dengan cara demikian akan menaikkan suhu dan energi dalam partikelpartikel fluida tersebut. Kedua, partikel-partikel tersebut akan bergerak ke daerah suhu yang lebih rendah dimana partikel tersebut akan bercampur dengan partikel-partikel fluida lainnya.

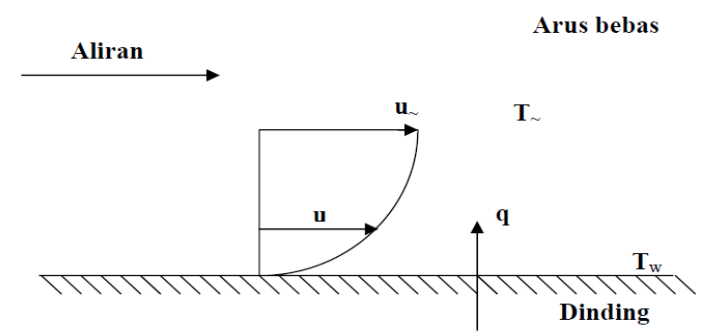

Gambar 2.1 Perpindahan Konveksi pada Suatu Plat(Holman J.P, 1994) 


\subsubsection{Perpindahan Kalor Radiasi}

Perpindahan kalor radiasi adalah proses perpindahan kalor yang terjadi dari benda yang bersuhu tinggi ke benda yang bersuhu rendah bila benda-benda itu terpisah di dalam ruang, bahkan bila terdapat ruang hampa di antara benda-benda tersebut. Mekanismenya adalah dengan pancaran, sinaran atau radiasi gelombang elektromagnetik. Perpindahan panas radiasi berlangsung dengan panjang gelombang pada interval tertentu.

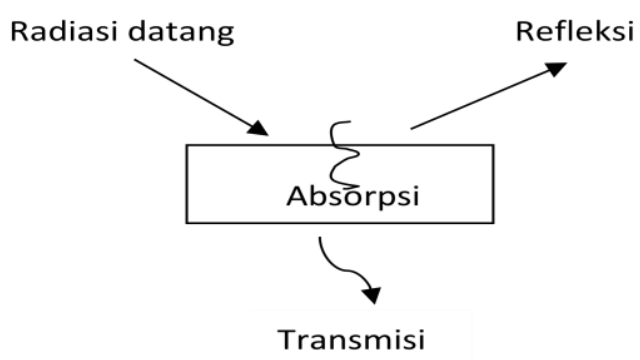

Gambar 2.2 Perpindahan Panas Radiasi

(Holman J.P, 1994)

Energi radiasi dikeluarkan oleh benda bersuhu tinggi kemudian dipindahkan melalui ruang antara, dalam bentuk gelombang elektromagnetik. Bila energi radiasi menimpa suatu bahan, maka sebagian radiasi dipantulkan, sebagian diserap, dan sebagian lagi diteruskan seperti pada gambar 2.2. Besarnya laju perpindahan panas adalah (Holman J.P, 1994).

\subsection{Alat Penukar kalor}

Penukar kalor (heat exchanger) adalah suatu alat yang digunakan untuk memindahkan panas dari suatu fluida ke fluida lainnya. Penukar kalor mempunyai banyak jenis. Berdasarkan fluidanya penukar kalor dibedakan menjadi tiga macam, yaitu aliran sejajar (paralel flow), aliran lawan arah (counter flow), dan aliran silang (crossflow).

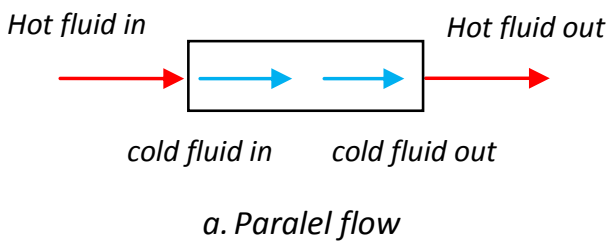

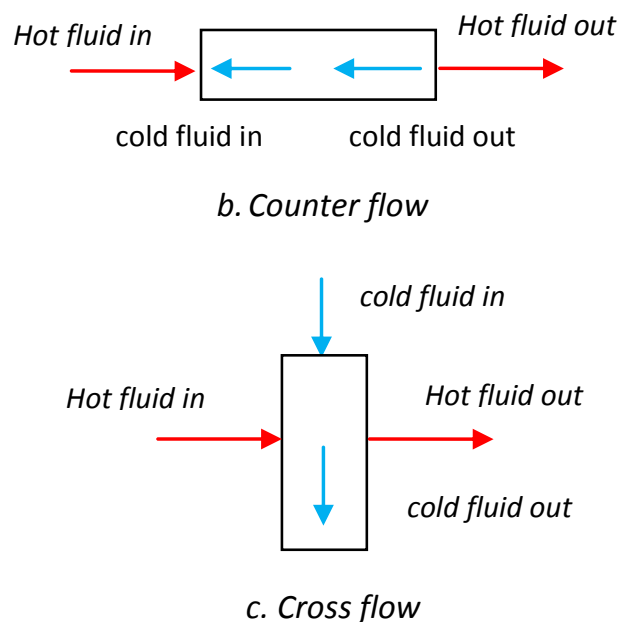

Gambar 2.3 Klasifikasi Penukar Kalor Berdasarkan Aliran Fluida(Widowati,2010)

\subsection{Sistem Pendinginan (Refrigerasi) \&} Pengkondisian Udara

\subsubsection{Sistem Refrigerasi}

Refrigerasi digunakan dengan tujuan untuk mendinginkan suatu ruang (lingkungan) atau benda. Cara kerja sistem pendinginan adalah pengeluaran kalor dari suatu ruangan, kemudian mempertahankan keadaannya sedemikian rupa sehingga temperaturnya lebih rendah dari temperatur lingkungannya. Pada prinsipnya pendinginan merupakan terapan dari teori perpindahan kalor dan termodinamika. Bahan yang digunakan dalam sistem pendinginan adalah refrigeran. Refrigeran adalah suatu zat yang mudah berubah fasanya dari cair menjadi uap dan sebaliknya apabila kondisi tekanan dan temperaturnya diubah. Sistem pendinginan yang paling sederhana memiliki komponen utama yaitu kompresor, kondensor, katup ekspansi, dan evaporator (Arismunandar, 2002).

\subsubsection{Jenis-jenis refrigerasi}

Jenis refrigerasi yang biasa ditemukanada dua jenis yaitu :

a. Refrigerasi Kompresi Uap / Vapour Compression Refrigeration (VCR). Menggunakan energi mekanis (kompresor) sebagai penggerak refrigerasinya. 


\section{b. Refrigerasi Penyerap Uap / Vapour Absorption Refrigeration (VAR). Menggunakan energi panas sebagai penggerak refrigerasinya.}

\subsubsection{Siklus pendinginan kompresi uap}

Siklus refrigerasi kompresi uap adalah siklus refrigerasi yang paling banyak digunakan. Prinsip kerja dari sistem pendinginan kompresi uap adalah kompresor menghisap uap refrigeran dari sisi keluar evaporator, tekanan dan temperatur diusahakan tetap rendah agar refrigeran senantiasa berada dalam fase gas. Didalam kompresor, uap refrigeran ditekan (dikompresi) sehingga tekanan dan temperatur tinggi. Energi yang diperlukan untuk kompresi diberikan oleh motor listrik atau penggerak mula lainnya.

Jadi, dalam proses kompresi, energi diberikan kepada uap refrigeran. Pada waktu uap refrigeran dihisap masuk ke dalam kompresor, temperatur masih rendah akan tetapi selama proses kompresi berlangsung, temperatur dan tekanan naik. Setelah proses kompresi, uap refrigeran (fluida kerja) mengalami proses kondensasi pada kondensor. Uap refrigeran yang bertekanan dan bertemperatur tinggi pada akhir kompresi dapat dicairkan dengan media pendingin fluida air atau udara.

Dengan kata lain, uap refrigeran memberikan panasnya (kalor laten pengembunan) kepada air pendingin atau udara pendingin melalui kondensor. Karena air pendingin menyerap panas dari refrigeran, maka temperaturnya menjadi lebih tinggi pada waktu keluar dari kondensor. Selama refrigeran mengalami perubahan dari fase gas (uap) ke fase cair, tekanan dan temperatur konstan, oleh karena itu pada proses ini refrigeran mengeluarkan energi dalam bentuk panas.

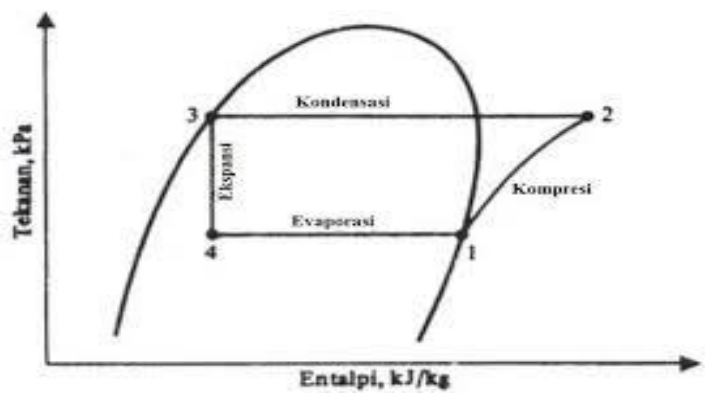

Gambar 2.5 Sistem kompresi uap (Dossat,1994)

Untuk menurunkan tekanan refrigeran cair dari kondensor dipergunakan katup ekspansi atau pipa kapiler. Melalui katup ekspansi, refrigeran mengalami proses evaporasi, yaitu proses penguapan cairan refrigeran pada tekanan dan temperatur rendah, proses ini terjadi pada evaporator. Selama proses evaporasi, refrigeran memerlukan atau mengambil energi dalam bentuk panas dari lingkungan atau sekelilingnya, sehingga temperatur sekeliling turun dan terjadi proses pendinginan.

\section{- Efek Pendinginan (ER)}

Dossat (1961) dalam Fahrani (2007) mengatakan banyaknya panas yang diserap oleh setiap $\mathrm{kg}$ refrigeran saat melalui evaporator disebut sebagai efek pendinginan. Besarnya efek pendinginan yang terjadi dapat dihitung dengan menggunakan persamaan di bawah ini :

$\mathrm{ER}=\left(h_{1}-h_{4}\right)$

dimana:

$h_{1}-h_{4}=$ perubahan entalpi refrigeran saat melalui evaporator (kJ/kg) (Nasution,2002 dalam Fahrani, 2007).

- Laju Aliran Massa

Laju aliran massa refrigeran dapat dihitung dengan membagi kapasitas daya mesin pendingin yang terdapat pada spesifikasi kapal dengan efek refrigerasi, sehingga :

Laju Aliran $\operatorname{Massa}(m)=\frac{Q_{e}}{E R}$. 
Dimana :

$\mathrm{Q}_{\mathrm{e}}=$ Kapasitas Daya Pendinginan

$\mathrm{ER}=$ Efek Refrigerasi

- Laju Aliran Volume

Laju aliran volume yang masuk ke kompresor dapat dihitung dengan mengetahui nilai dari volume spesifik refrigeran R-22 pada temperature tertentu atau saat refrigeran masuk ke kompresor. Nilai dari volume spesifik refrigeran R-22 dapat dilihat pada Tabel A-7 pada saat kondisi uap jenuh.

Laju Aliran Volume $=m x v_{g}$

Dimana :

$m=$ Laju Aliran Massa

$v_{g}=$ Volume Spesifik Refrigeran

\section{- $\mathrm{COP}$}

Performansi mesin pendingin yang disebut juga dengan koefisien prestasi (Coefficient of Perfomance) dinyatakan sebagai perbandingan antara kapasitas pendinginan yang terjadi dengan kerja yang dilakukan kompresor (Stoecker dan Jones, 1982). Dapat dihitung dengan menggunakan persamaan :

$\mathrm{COP}=\frac{Q_{e}}{W_{\text {in }}}$

Dimana :

$\mathrm{Q}_{\mathrm{e}}$ : Daya / Kapasitas Pendinginan

$\mathrm{W}_{\text {in }}$ : Kerja Kompresor

- Efisiensi

Merupakan kebalikan dari Koefisien Prestasi yaitu merupakan hasil bagi antara Kerja Kompresor dengan Kapasitas Pendinginan. Dimana dirumuskan dengan persamaan :

Efisiensi $=\frac{W_{\text {in }}}{Q_{\mathrm{e}}}$

\subsubsection{Sistem pengkondisian udara}

Sistem pengkondisian udaraadalah
sistem yang mengkondisikan udara, mendistribusikan, dan dikombinasikan dengan udara luar ke dalam ruang atau lingkungan serta pada saat yang bersamaan mengontrol / mengendalikan dan mempertahankan temperatur ruang yang dibutuhkan, kelembaban, aliran udara, tingkat kebisingan suara dan perbedaan tekanan dalam yang telah ditentukan untuk tujuan kesehatan dan kenyamanan penghuni, benda dalam ruang, pengolahan produk dan lainnya.

\subsection{Komponen Mesin Pendingin}

\subsubsection{Kompresor}

Kompresor merupakan jantung dari sistem refrigerasi. Sistem kerja kompresor adalah menghisap uap refrigeran dan mendorongnya dengan cara sehingga tekanan uap refrigeran naik sampai ke tekanan yang diperlukan untuk pengembunan (kondensasi) uap refrigeran di dalam kondensor

Analisa performa suatu kompresor dapat dilakukan pada suhu kondensasi dan evaporasi yang tetap. Saat suhu kondensasi tetap, dengan semakin rendahya suhu evaporasi, maka perbandingan tekanan masuk dan keluar kompresor mengalami penurunan. Laju aliran refrigeran mengalami penurunan dan volume spesifiknya naik, menyebabkan laju alliran massa refrigeran berkurang. Saat suhu evaporasi menurun, kapasitas pendinginan berkurang.

adalah :

Daya yang di butuhkan kompresor

$\mathrm{W}_{\text {in }}=m\left(h_{2}-h_{1}\right)$

Dimana :

$\mathrm{W}_{\text {in }}=$ Kerja kompresor

$m$ = laju aliran massa refrigeran $(\mathrm{kg} / \mathrm{s})$

Saat suhu evaporasi menurun perbedaan entalpi akan naik sedangkan laju aliran massa mengalami penurunan dan menyebabkan daya 
yang dibutuhkan kompresor akan meningkat. Namun pada suhu evaporasi yang makin rendah, komsumsi daya cenderung menurun. Hal ini menyebabkan COP mesin pendingin tersebut menurun.

\subsubsection{Kondensor}

Kondensor adalah alat penukar panas, kondesor membuang panas ke lingkungan. Di kondensor akan terjadi proses perubahan fasa refrigeran, dari fasa uap menjadi fasa cair. Proses kondensasi akan berlangsung apabila refrigeran dapat melepaskan kalor yang dikandungnya. Panas akan dilepaskan dan dibuang ke lingkungan. Agar panas dapat dilepaskan ke lingkungan,maka suhu kondensasi (Tkd) harus lebih tinggi dari suhu lingkungan (Tling). Refrigeran adalah zat yang sangat mudah menguap, supaya dapat dikondensasikan refrigeran seharusnya bertekanan tinggi. Proses pelepasan panas di kondensor dilakukan dengan menggunakan medium pendingin. Medium pendingin yang umum digunakan adalah air dan udara. Menurut Dossat (1961) panas dari refrigeran dapat meningkatkan suhu medium pendingin.

\subsubsection{Katup Ekspansi}

Katup ekspansi berfungsi untuk menurunkan tekanan refrigeran yang keluar dari kondensor. Ada 4 jenis katup ekspansi yang umum digunakan yaitu tipe pipa kapiler, superheat- controlled expansion valve, float valve dan constant pressure expansion valve. Katub expansi tipe kapiler sesuai dengan mesin pendingin yang mempunyai mempunyai beban pendingin yang tetap. Constant pressure expansion valve bekerja dengan cara mempertahankan tekanan tetap pada daerah sebelum evaporator. Katub expansi jenis Float valve bekerja dengan cara mempertahankan cairan refrigeran di evaporator pada ketinggian yang tetap. Superheat- controlled expansion valve bekerja karena adanya gas lewat panas yang meninggalkan evaporator (Stoecker dan Jones, 1982).

\subsubsection{Evaporator}

Jurnal Kajian Teknik Mesin

Vol. 2 No. 1 April 2017
Selain kondensor, evaporator juga disebut alat penukar penas. Evaporator menyerap panas dari luar. Evaporator juga mengubah refrigeran cair menjadi gas. evaporator berfungsi untuk menguapkan refrigeran cair setelah suhu dan tekanannya diturunkan oleh katup ekspansi (Stoecker dan Jones, 1982).

Setelah refrigeran diekspansikan secara irreversibel adiabatik menjadi cairan jenuh, refrigeran akan memiliki tekanan dan temperatur rendah sehingga akan menerima sejumlah kalor dari lingkungan yang didinginkan dan refrigeran berubah seluruhnya menjadi uap jenuh yang kemudian masuk ke kompresor untuk disirkulasikan kembali. Komponen evaporator ini yang secara langsung berhubungan dengan produk yang akan didinginkan.

\subsection{Refrigeran}

Refrigeran adalah fluida kerja yang bersirkulasi dalam siklus refrigerasi. Secara umum refrigeran merupakan benda atau zat yang bertindak sebagai agen pendingin dengan cara menyerap panas dari ruang atau zat lain. Berkaitan dengan siklus kompresi uap, refrigeran adalah fluida kerja siklus yang bergantian menguap dan mengembun karena menyerap dan melepaskan kalor.

Harus diakui di awal bahwa tidak ada refrigeran yang ideal, karena perbedaan dalam kondisi dan persyaratan dari berbagai aplikasi, tidak satupun refrigeran yang secara umum cocok untuk semua aplikasi.Tetapi paling tidak mendekati ideal itupun hanya sebatas sifatsifatnya memenuhi kondisi dan syarat-syarat dari aplikasi yang akan digunakan.

\subsubsection{R-22}

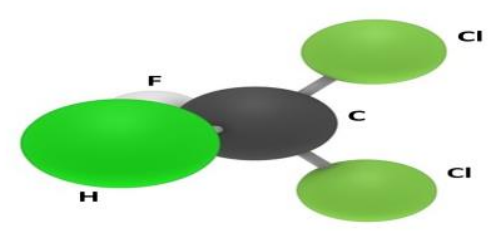

Gambar 2.6 Struktur refrigeran R-22 
Refrigeran R-22 Termasuk dalam senyawa halokarbon, refrigeran ini banyak digunakan, tidak mudah terbakar serta sangat stabil. Nama kimia dari R-22 adalah Monoklorodifluorometana dengan rumus kimia $\mathrm{CHClF}_{2}$.

\subsubsection{MC-22}

MC-22 sebagai refrigeran alternatif untuk menggantikan refrigeran R-22. Refrigeran ini mengandung propana yang sangat tinggi yaitu $99,7 \%$ dan 0.03 adalah iso butane.

Tabel 2.5 Perbandingan sifat fisika dan termodinamika MC-22 dan R-22

\begin{tabular}{|c|c|c|c|}
\hline NO & PARAMETER & MC-22 & R-22 \\
\hline 1 & $\begin{array}{c}\text { Panas Jenis } \\
\text { Cairan Jenuh pd } \\
37,8^{\circ} \mathrm{C}, \mathrm{Kj} / \mathrm{Kg}\end{array}$ & 2,909 & 1,325 \\
\hline 2 & $\begin{array}{c}\text { Panas Jenis Uap } \\
\text { Jenuh pd } 37,8^{\circ} \mathrm{C} \\
\mathrm{Kj} / \mathrm{Kg}\end{array}$ & 2,238 & 0,9736 \\
\hline 3 & $\begin{array}{c}\text { Konduktivitas } \\
\text { Termal Cairan } \\
\text { Jenuh pd } 37,8^{\circ} \mathrm{C} \text {, } \\
\text { w/m }\end{array}$ & 0,0868 & 0,0778 \\
\hline 4 & $\begin{array}{c}\text { Konduktivitas } \\
\text { Termal Uap } \\
\text { Jenuh pd } 37,8^{\circ} \mathrm{C} \text {, } \\
\text { w/m }\end{array}$ & 0,0211 & 0,0128 \\
\hline 5 & $\begin{array}{c}\text { Kerapatan Cairan } \\
\text { Jenuh pd } 37,8^{\circ} \mathrm{C} \\
\left(\mathrm{kg} / \mathrm{m}^{3}\right)\end{array}$ & 471,30 & $1.138,0$ \\
\hline 6 & $\begin{array}{c}\text { Kerapatan Cairan } \\
\text { Jenuh pd } 37,8^{\circ} \mathrm{C}, \\
\left(\mathrm{kg} / \mathrm{m}^{3}\right)\end{array}$ & 28,53 & 62,46 \\
\hline 7 & $\begin{array}{c}\text { Kerapatan Uap } \\
\text { Jenuh pd } 37,8^{\circ} \mathrm{C} \\
\left(\mathrm{kg} / \mathrm{m}^{3}\right)\end{array}$ & 2,412 & 4,705 \\
\hline 8 & $\begin{array}{c}\text { Viskositas Cairan } \\
\text { Jenuh pd } 37,8^{\circ} \mathrm{C} \\
\text { (uPa-s) }\end{array}$ & 84,58 & 143,10 \\
\hline
\end{tabular}

\begin{tabular}{|c|c|c|c|}
\hline 9 & $\begin{array}{c}\text { Viskositas Uap } \\
\text { Jenuh pd } 37,8^{\circ} \mathrm{C} \\
\text { (uPa-s) }\end{array}$ & 9,263 & 13,39 \\
\hline
\end{tabular}

\section{METODOLOGI PENELITIAN}

\subsection{Alir Metodologi Penelitian}

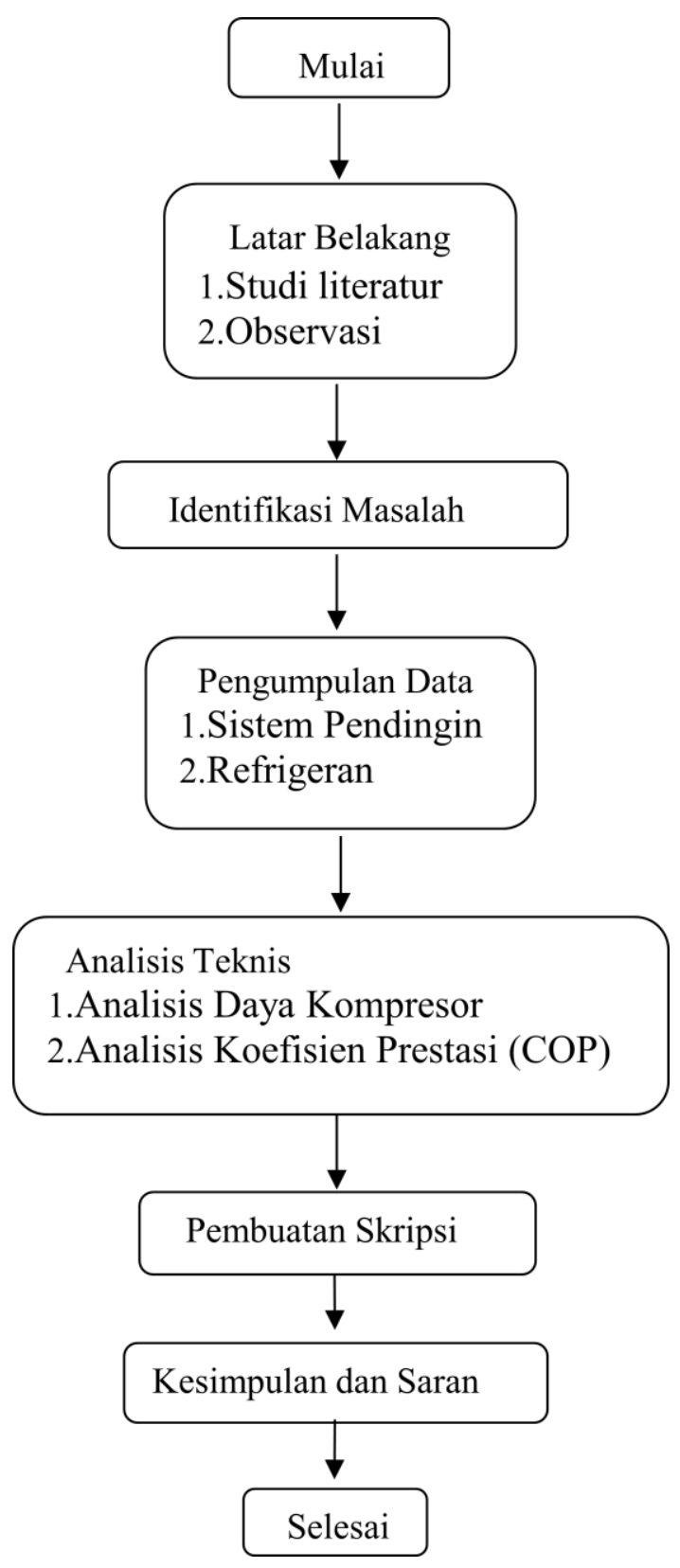




\subsection{Pengumpulan Data}

Pengumpulan data diperlukan untuk penunjang dalam menghitung kinerja sistem pendinginan ruang palkah kapal purseine kapasitas 100 ton dengan langkah-langkah sebagai berikut :

1. Menghitung efek pendinginan dari refrigeran R-22 dan MC-22

2. Menghitung laju aliran refrigeran R-22 dan MC-22

3. Menghitung COP dari refrigeran $\mathrm{R}-22$ dan MC-22

4. Menghitung daya kompresor dari masukan refrigeran R-22 dan MC-22

\subsection{Hipotesis Penelitian}

Berdasarkan rumusan masalah dan analisis kerangka pemikiran di atas dapat diambil hipotesis yaitu :

'Penggantian refrigeran dengan MC-22 berpengaruh terhadap COP dan daya kompresor yang dibutuhkan.'

\section{DATA DAN PEMBAHASAN}

\subsection{Deskripsi Data Kapal}

\subsection{Deskripsi Data Refrigeran}

Tabel 4.1 Perbandingan sifat refrigeran jenuh R-22 dan MC-22 (propana)

\begin{tabular}{|c|c|c|c|c|c|c|c|c|}
\hline \multirow[b]{3}{*}{$\begin{array}{l}\text { Temp. } \\
{ }^{\circ} \mathrm{C}\end{array}$} & \multicolumn{4}{|c|}{ R-22 } & \multicolumn{4}{|c|}{ MC-22 } \\
\hline & \multirow[b]{2}{*}{$\begin{array}{c}\text { Tekanan } \\
\text { (bar) }\end{array}$} & \multicolumn{3}{|c|}{ Entalpi $(\mathrm{kJ} / \mathrm{kg})$} & \multirow[b]{2}{*}{$\begin{array}{c}\text { Tekanan } \\
\text { (bar) }\end{array}$} & \multicolumn{3}{|c|}{ Entalpi $(\mathrm{kJ} / \mathrm{kg})$} \\
\hline & & $\begin{array}{c}\text { Cair } \\
\text { Jenuh } \\
(h f)\end{array}$ & $\begin{array}{l}\text { Evap. } \\
\text { (hfg ) }\end{array}$ & $\begin{array}{l}\text { Uap } \\
\text { Jenuh } \\
\text { (hg) }\end{array}$ & & $\begin{array}{c}\text { Cair } \\
\text { Jenuh } \\
(h f)\end{array}$ & $\begin{array}{l}\text { Evap. } \\
\text { (hfg) }\end{array}$ & $\begin{array}{c}\text { Uap } \\
\text { Jenuh } \\
\text { (hg) }\end{array}$ \\
\hline-20 & 2,453 & 22,17 & 219,91 & 242,09 & $2,4,444$ & "46,3 & "400,5 & $\overline{4446,8}$ \\
\hline 0 & 4,981 & 45,12 & 204,81 & 249,92 & 4,743 & 95,1 & 374,5 & 469,6 \\
\hline 32 & 12,556 & 84,14 & 175,18 & 259,32 & 11,33 & 180,2 & 322,4 & 502,6 \\
\hline 40 & 15,341 & 94,53 & 166,25 & 260,79 & 13,69 & 203,1 & 306,5 & 509,6 \\
\hline
\end{tabular}

Dikondisikan refrigeran dalam proses pendinginan, uap refrigeran keluar dari evaporator dengan temperatur $-20^{\circ} \mathrm{C}$. Refrigeran keluar dari kompresor dengan
- Data Utama Kapal Ikan,

Nama Kapal

: KM Putra Berlian

Tahun Pembuatan : : 2014

Panjang : 21,5 meter

Lebar $\quad: 9$ meter

Tinggi Badan Kapal : 2,7 meter

Jenis Kapal : Purse Seine

Daya Mesin Pendingin : 2x30 kW

- Data Mesin Utama Kapal,

Main Engine $\quad$ : Fuso 6D70

Bahan Bakar : Solar

Isi Silinder $\quad: 10.308 \mathrm{cc}$

Kapasitas Kerja $\quad: 158 \mathrm{KW}$

Torsi Max.

: $686 \mathrm{Nm}(70 / 1600$

$\mathrm{kgn} / \mathrm{rpm})$

Daya Max. $\quad: 215 / 2500$ (Ps/rpm)

- Data Ruang Penyimpanan Ikan (Palkah),

$\begin{array}{ll}\text { Tinggi } & : 4 \text { Meter } \\ \text { Lebar } & : 4 \text { Meter } \\ \text { Panjang } & : 2,5 \text { Meter } \\ \text { Kapasitas / Lubang } & : 8 \text { Ton } \\ \text { Jumlah } & : 12 \text { Lubang Palkah } \\ \text { Suhu Dalam Palkah } & :-20^{\circ} \mathrm{C}\end{array}$


Tabel 4.2 Kondisi refrigeran R-22 dalam proses pendinginan

\begin{tabular}{|l|c|c|c|}
\hline \multicolumn{1}{|c|}{ Kondisi Refrigeran } & $\begin{array}{c}\text { Tekanan } \\
(\mathrm{kpa})\end{array}$ & $\begin{array}{c}\text { Temperature } \\
\left({ }^{\circ} \mathrm{C}\right)\end{array}$ & $\begin{array}{c}\text { Enthalpi } \\
(\mathrm{kJ} / \mathrm{kg})\end{array}$ \\
\hline Uap refrigeran keluar evaporator dan masuk ke kompresor & 245,34 & -20 & 242,09 \\
\hline Refrigeran keluar dari kompresor dan masuk ke kondensor & 1534,1 & 40 & 260,79 \\
\hline Refrigeran keluar kondensor dan masuk katup ekspansi & 1255,6 & 32 & 84,14 \\
\hline Refrigeran keluar katup ekspansi dan menuju evaporator & 245,34 & -20 & 22,17 \\
\hline
\end{tabular}

\subsection{Penghitungan Pada Refrigeran R-22}

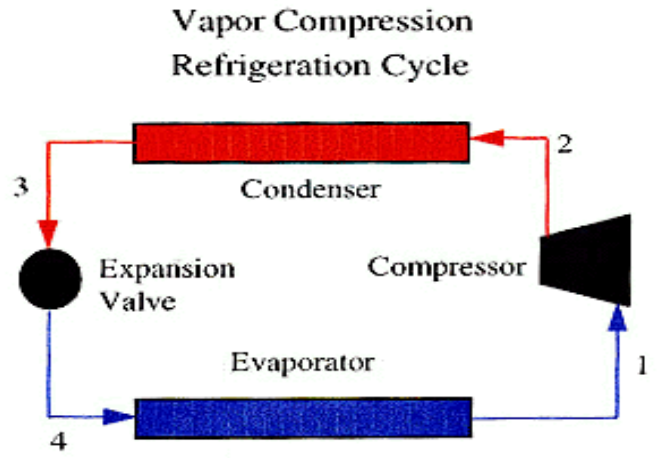

Gambar 4.1 Siklus Refrigerasi Kompresi Uap Kondisi 1 : Kompresi isentropis dalam Kompresor refrigeran dalam kondisi uap jenuh $\left(\mathrm{h}_{\mathrm{g}}\right)$ Kondisi 2 : Pembuangan kalor secara isobaris dalam kondensor refrigeran dalam kondisi uap panas lanjut $\left(\mathrm{h}_{\mathrm{g}}\right)$ Kondisi 3 : Throttling dalam katup ekspansi atau tabung kapiler refrigeran dalam kondisi cairan jenuh $\left(\mathrm{h}_{\mathrm{f}}\right)$ Kondisi 4 : Penyerapan kalor secara isobaris dalam evaporator refrigeran dalam kondisi campuran jenuh $\mathrm{h}_{4}=$ $\mathrm{h}_{3}\left(\mathrm{~h}_{\mathrm{f}}\right)$

\section{a. Efek Refrigerasi (ER)}

$$
\begin{aligned}
\mathbf{E R} & =h_{1}-h_{4} \\
& =242,09 \mathrm{~kJ} / \mathrm{kg}-22,17 \mathrm{~kJ} / \mathrm{kg} \\
& =219,92 \mathrm{~kJ} / \mathrm{kg}
\end{aligned}
$$

\section{b. Laju Aliran Refrigeran}

$$
\begin{aligned}
\boldsymbol{m} & =\frac{\text { Kapasitas daya pendinginan }}{\text { Efek Refrigerasi }} \\
& =\frac{2 \times 30 \mathrm{~kW}}{219,92 \mathrm{~kJ} / \mathrm{kg}}
\end{aligned}
$$

Jurnal Kajian Teknik Mesin

Vol. 2 No. 1 April 2017

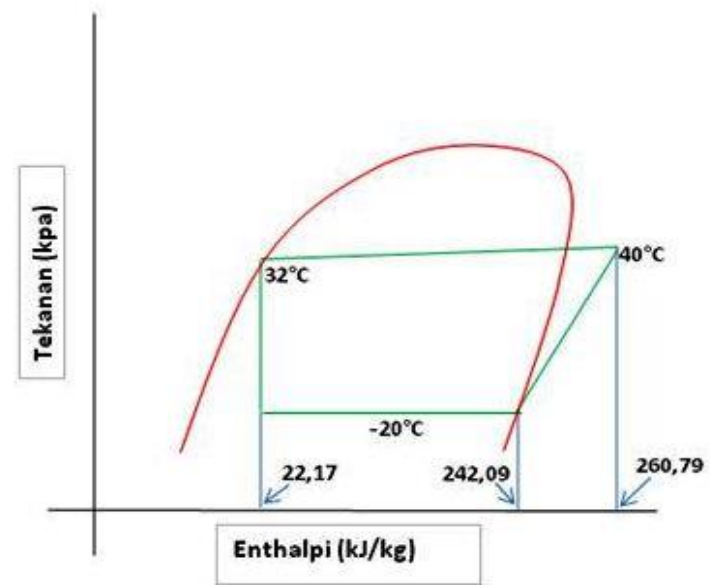

Gambar 4.2 Siklus refrigeran kompresi uap

$$
=0,2728 \mathrm{~kg} / \mathrm{s}
$$

\section{c. Kerja Kompresor}

$242,09 \mathrm{~kJ} / \mathrm{kg}$ )

$$
\begin{aligned}
& \boldsymbol{W}_{\text {in }}=m\left(h_{2}-h_{1}\right) \\
& \quad=0,2728 \mathrm{~kg} / \mathrm{s} \quad(260,79 \mathrm{~kJ} / \mathrm{kg}- \\
& \mathrm{kJ} / \mathrm{kg}) \\
& \quad=0,2728 \mathrm{~kg} / \mathrm{s} \times 18,7 \mathrm{~kJ} / \mathrm{kg} \\
& \quad=5,10136 \mathrm{~kW}
\end{aligned}
$$

\section{d. COP/Koefisien Prestasi}

$$
\begin{aligned}
\boldsymbol{C O P} & =\frac{Q_{e}}{W_{\text {in }}} \\
& =\frac{60 \mathrm{~kW}}{5,10135 \mathrm{~kW}} \\
& =11,7616
\end{aligned}
$$

\section{e. Laju Aliran Volume}

$$
\begin{aligned}
& =m \times v_{g} \\
& =0,2728 \mathrm{~kg} / \mathrm{s} \times 0,0926 \mathrm{~m}^{3} / \mathrm{kg} \\
& =0,02526 \mathrm{~m}^{3} / \mathrm{s}
\end{aligned}
$$

dengan konversi $1 \mathrm{~m}^{3} / \mathrm{s}=1000 \mathrm{~L} / \mathrm{s}$

sehingga, 
Laju Aliran Volume $=0,02526 \mathrm{~m}^{3} / \mathrm{s}$ x 1000

$$
=25,26 \mathrm{~L} / \mathrm{s}
$$

$$
\begin{aligned}
& =\frac{5,10136 \mathrm{~kW}}{60 \mathrm{~kW}} \\
& =0,085
\end{aligned}
$$

\section{f. Efisiensi}

$$
\text { Efisiensi }=\frac{W_{\text {in }}}{\mathrm{Q}_{\mathrm{e}}}
$$

4.4 Penghitungan pada Refrigeran MC-22

Tabel 4.3 Kondisi Refrigeran Hidrokarbon pada Proses Pendinginan

\begin{tabular}{|l|c|c|c|}
\hline \multicolumn{1}{|c|}{ Kondisi Refrigeran } & $\begin{array}{c}\text { Tekanan } \\
(\mathrm{kpa})\end{array}$ & $\begin{array}{c}\text { Temperature } \\
\left({ }^{\circ} \mathrm{C}\right)\end{array}$ & $\begin{array}{c}\text { Enthalpi } \\
(\mathrm{kJ} / \mathrm{kg})\end{array}$ \\
\hline Uap refrigeran keluar evaporator dan masuk ke kompresor & 244,4 & -20 & 446,8 \\
\hline Refrigeran keluar dari kompresor dan masuk ke kondensor & 1369 & 40 & 509,6 \\
\hline Refrigeran keluar kondensor dan masuk katup ekspansi & 1133 & 32 & 180,2 \\
\hline Refrigeran keluar katup ekspansi dan menuju evaporator & 244,4 & -20 & 46,3 \\
\hline
\end{tabular}

Dengan cara penghitungan yang sama pada refrigeran R-22 maka didapat pula hasihasil penghitungan pada refrigeran MC-22 sebagai berikut :

a. Efek Refrigerasi (ER)

$$
\begin{aligned}
\mathbf{E R} & =h_{1}-h_{4} \\
& =446,8 \mathrm{~kJ} / \mathrm{kg}-46,3 \mathrm{~kJ} / \mathrm{kg} \\
& =400,5 \mathrm{~kJ} / \mathrm{kg}
\end{aligned}
$$

\section{b. Laju Aliran Refrigeran}

$$
\begin{aligned}
\boldsymbol{m} & =\frac{\text { Kapasitas daya pendinginan }}{\text { Efek Refrigerasi }} \\
& =\frac{2 \times 30 \mathrm{~kW}}{400,5 \mathrm{~kJ} / \mathrm{kg}} \\
& =0,1498 \mathrm{~kg} / \mathrm{s}
\end{aligned}
$$

\section{c. Kerja Kompresor} $446,8 \mathrm{~kJ} / \mathrm{kg})$

$$
\begin{aligned}
\boldsymbol{W}_{\text {in }} & =m\left(h_{2}-h_{1}\right) \\
& =0,1498 \quad \mathrm{~kg} / \mathrm{s} \quad(509,6 \mathrm{~kJ} / \mathrm{kg}-
\end{aligned}
$$

$$
=9,407 \mathrm{~kW}
$$

\section{d. COP/Koefisien Prestasi}

$$
\begin{aligned}
\boldsymbol{C O P} & =\frac{Q_{e}}{W_{i n}} \\
& =\frac{60 \mathrm{~kW}}{9,407 \mathrm{~kW}} \\
& =6,379
\end{aligned}
$$

\section{e. Laju Aliran Volume}

$$
\begin{aligned}
& =m \times v_{g} \\
= & 0,1498 \mathrm{~kg} / \mathrm{s} \times 0,1815 \mathrm{~m}^{3} / \mathrm{kg} \\
= & 0,02718 \mathrm{~m}^{3} / \mathrm{s}
\end{aligned}
$$

dengan konversi $1 \mathrm{~m}^{3} / \mathrm{s}=1000 \mathrm{~L} / \mathrm{s}$

sehingga,

Jurnal Kajian Teknik Mesin

Vol. 2 No. 1 April 2017
Laju Aliran Volume $=0,02718 \mathrm{~m}^{3} / \mathrm{s} \times 1000$ $=27,18 \mathrm{~L} / \mathrm{s}$

\section{f. Efisiensi}

$$
\begin{aligned}
\text { Efisiensi } & =\frac{W_{\text {in }}}{Q_{\mathrm{e}}} \\
& =\frac{9,407 \mathrm{~kW}}{60 \mathrm{~kW}} \\
& =0,1567
\end{aligned}
$$

\subsection{Pembahasan}

Dari perhitungan di atas didapatkan hasil-hasil yang dapat dilihat perbandingan antara refrigeran R-22 dan MC-22 pada tabel berikut :

Tabel 4.4 Hasil perbandingan R-22 dan MC-22

\begin{tabular}{|l|c|c|}
\hline \multicolumn{1}{|c|}{ Parameter } & R-22 & MC-22 \\
\hline $\begin{array}{l}\text { Laju aliran massa } \\
\text { refrigeran (kg/s) }\end{array}$ & 0,2728 & 0,1498 \\
\hline Kerja kompresor (kW) & 5,10136 & 9,407 \\
\hline $\begin{array}{l}\text { Koefisien prestasi } \\
(\mathrm{COP})\end{array}$ & 11,7616 & 6,379 \\
\hline Laju aliran volume (L/s) & 25,26 & 27,18 \\
\hline Efisiensi (kW/TR) & 0,085 & 0,1567 \\
\hline
\end{tabular}

Dari hasil penelitian yang dilakukan pada kedua jenis refrigeran yaitu antara refrigeran R-22 dan refrigeran hidrokarbon MC-22 didapat hasil yang berbeda dengan 
teori. Secara keseluruhan,refrigeran R-22 masih lebih baik dibandingkan MC-22. Untuk kapasitas daya pendinginan yang sama yaitu 60 $\mathrm{kW}, \mathrm{R}-22$ memerlukan kerja kompresor $5,10136 \mathrm{~kW}$ sedangkan MC-22 memerlukan 9,407 kW. Jadi selisih kerja kompresor (R-22 dan MC-22) 4,305 $\mathrm{kW}$ atau penurunan kerja sebesar $45 \%$.

Nilai COP refrigeran R-22 sebesar 11,7616 sedangkan nilai COP refrigeran MC22 sebesar 6,379 atau COP R-22 lebih besar dari MC-22. Hal serupa juga terlihat pada efisiensi (kW/TR). Efisiensi refrigeran R-22 yang lebih baik dari refrigeran MC-22. Masingmasing terdapat penurunan baik COP maupun efisiensi sebesar $45 \%$ saat penggantian menggunakan MC-22.

Namun nilai laju aliran dari refrigeran MC-22 lebih rendah yaitu sebesar $0,1498 \mathrm{~kg} / \mathrm{s}$ sedangkan R-22 sebesar $0,2728 \mathrm{~kg} / \mathrm{s}$. Hal ini disebabkan karena efek refrigerasi (ER) dari refrigeran MC-22 lebih besar bila dibandingkan dengan R-22. Dengan begitu menunjukkan bahwa refrigeran MC-22 dapat menghemat penggunaan refrigeran karena memerlukan pengisian yang lebih sedikit dibandingkan dengan R-22.

\section{KESIMPULAN}

Kesimpulan yang didapat dari hasil penghitungan dan pembahasan data-data yang dikumpulkan dalam Analisis Kinerja Sistem Pendingin Ruang Palkah Ikan dengan Menggunakan Refrigeran R-22 dan Hidrokarbon MC-22 adalah sebagai berikut :

1. Penggantian refrigeran R-22 dengan MC-22 didapat hasil yang kurang optimal. Secara keseluruhan penggunaan refrigeran $\mathrm{R}$ 22 masih lebih baik dari pada MC-22 baik dalam kinerja kompresor, efisiensi maupun COP. Hal ini dikarenakan pada sistem refrigerasi menggunakan desain yang khusus digunakan untuk refrigeran R-22. Dan terjadinya penurunan kinerja kompresor, efisiensi serta COP pada penggunaan refrigeran hidrokarbon MC-22 diakibatkan karena hal di atas dan adanya rugi-rugi kalor yang tidak terdefinisi dan tidak dihitung.
2. Pemilihan antara refrigeran R-22 dan hidrokarbon MC-22 masing-masing mempunyai kelebihan dan kekurangan, yaitu :

\begin{tabular}{l} 
R-22 \\
Kelebihan \\
\hline 1. Mempunyai nilai efisiensi, kinerja \\
kompresor dan COP yang lebih baik \\
daripada MC-22 dalam aplikasi pada sistem \\
pendingin ikan KM Putra Berlian \\
2. Relatif lebih aman digunakan pada kapal \\
ikan dengan mobilitas tinggi dan sering \\
terjadi goncangan ombak karena memiliki \\
sifat yang tidak mudah terbakar \\
Kekurangan \\
1. Merupakan golongan HCFC yang akan \\
dilarang penggunaanya setelah tahun 2030 \\
sesuai Protokol Montreal \\
2. Mempunyai nilai ODP 0,05 dan nilai GWP \\
1700, artinya dapat menyebabkan penipisan \\
lapisan ozon dan menyebabkan pemanasan \\
global \\
3. Memiliki aliran massa yang relatif lebih besar \\
yaitu 0,2728 kg/s yang berdampak pada \\
penggunaan refrigeran yang lebih banyak
\end{tabular}

\begin{tabular}{|l|}
\hline MClebihan \\
\hline 1. Merupakan refrigeran golongan hidrokarbon \\
yang sangan ramah lingkungan karena tidak \\
memiliki nilai ODP maupun GWP artinya \\
tidak merusak lapisan ozon dan tidak \\
menyebabkan pemanasan global \\
2. Memiliki aliran massa yang lebih kecil yaitu \\
0,1498 kg/s yang berdampak pada \\
penggunaan refrigeran yang lebih sedikit. \\
\hline $\begin{array}{l}\text { Kekurangan } \\
\text { 1. Mempunyai nilai efisiensi, kinerja } \\
\text { kompresor dan COP yang lebih rendah } \\
\text { daripada R-22 }\end{array}$ \\
\hline
\end{tabular}


2. Sifatnya yang dapat merambatkan api membuat banyak pengusaha kapal enggan untuk memakai jenis refrigeran ini

\section{SARAN}

Dalam memilih dan menentukan refrigeran untuk sistem pendinginan kapal ikan lebih diutamakan adalah kinerja, efisiensi dan COP namun tidak dikesampingkan pula mengenai dampak dari pemakaian refrigeran tersebut baik dampak secara teknis, dampak ekonomi, aspek keselamatan dan tidak kalah pentingnya yaitu dampak lingkungan.

Untuk mendapatkan hasil yang lebih akurat mengenai analisis daya kompresor, efisiensi dan COP yang dihasilkan dari refrigeran hidrokarbon MC-22 perlu dilakukan pengujian langsung pada kapal yang ingin diuji.

\section{DAFTAR PUSTAKA}

Dossat,Roy J. 2002. Principles of Refrigeration. New York : Prentice Hall.

Holman, J.P. 1972. Heat Transfer. Third Edition. New York : McGraw-Hill Kogakusha, Ltd.

Stoeker, Wilbert F. and Jones, Jerold W. 1983. Refrigeration and Air Conditioning. Second Edition. New York : McGraw-Hill, Inc.

Illyas, S. 1983. Teknologi Refrigerasi Hasil Perikanan. Jakarta : CV. Paripurna

Arora, C.P. 2000. Refrigeration and Air Conditioning. Second Edition. New Delhy : Tata McGraw-Hill Publishing Company, Ltd.

Sumanto. 1985. Dasar-Dasar Mesin Pendingin. Yogyakarta : Penerbit Andi.

Moran, Michael J. dan Shapiro,Howard N. 1992. Termodinamika Teknik. Jilid 1. Edisi 4. Jakarta.
American Society of Heating Refrigerating, and Air-Conditioning Engineers (ASHRAE). Refrigeration. SI Edition.

Gunther, Raymond C. 1998. Refrigeration, Air Conditioning, and Cold Storage. Philadelphia : Chilton Company.

\section{Dupont $^{\mathrm{TM}}$ Suva Refrigerant. Technical Information : Thermodynamic Properties of Froen ${ }^{R} 22$ (T-22-SI).}

Musicool-Datasheet : Data Teknis dan Spesifikasi Musicool Hydrocarbon Refrigerant. PH Diagram Musicool MC-22. 